\title{
Social Welfare under Quantity Competition and Price Competition in a Mixed Duopoly with Network Effects: An Analysis*
}

\author{
Yasuhiko Nakamura \\ College of Economics, Nihon University, Tokyo, Japan \\ Email: yasuhiko.r.nakamura@gmail.com
}

Received May 6, 2013; revised June 6, 2013; accepted July 6, 2013

Copyright (C) 2013 Yasuhiko Nakamura. This is an open access article distributed under the Creative Commons Attribution License, which permits unrestricted use, distribution, and reproduction in any medium, provided the original work is properly cited.

\begin{abstract}
In their recent work, Matsumura and Ogawa (2012) showed that in the context of a mixed duopoly, equilibrium social welfare is higher in price-setting competition than in quantity-setting competition. We found that when the strength of network effects is sufficiently high, the above result is totally reversed; thus, in a mixed duopoly, the presence of network effects weakens the superiority of price-setting competition with respect to equilibrium social welfare.
\end{abstract}

Keywords: Mixed Duopoly; Network Effect; Price Competition; Quantity Competition

\section{Introduction}

This study compares equilibrium social welfare between price-setting competition and quantity-setting competition in a mixed duopoly with network effects. The network effects that we consider in this paper were introduced in Katz and Shapiro [1] and applied in Hoernig [2], Nakamura [3], and Nakamura [4]. These effects reflected a simple mechanism where the surplus obtained by a firm's client increases directly with the number of other clients of this firm. In this study, we show that when the strength of such network effects is sufficiently high, the equilibrium social welfare is higher in a quantity-setting competition than in a price-setting competition; this finding is strikingly different from those in the existing literature in this field including Ghosh and Mitra [5] and Matsumura and Ogawa [6].

Although we can consider the European automobile industry as a representative example in a mixed oligopolistic industry, as described in Katz and Shapiro [1], network effects as positive consumption externalities are likely to arise in the automobile market ${ }^{1}$. In such an in-

\footnotetext{
"We are grateful for the financial support by KAKENHI (25870113). All remaining errors are our own.

${ }^{1}$ As one example, a Spanish public-owned automobile manufacturer, SEAT competes with Volkswagen which is one of the most famous German private automobile manufacturers. In addition, Renault which is the most famous partially French public-owned firm competes with many private firms in Europe. Recently, Romanian private firm, Dacia merged with Renault, and it became a second marque for the Renault group. See Barcena-Ruiz and Garzon [7] for other examples and detail discussions of the European automobile industry as a mixed oligopolistic market.
}

dustry, foreign automobile firms' sales may be less than expected because of the perceptions that consumers hold about the less experienced and smaller service networks of new or less popular brands. Thus, in a mixed oligopoly, the presence of network effects as positive consumption externalities should be analyzed since they influence the equilibrium market outcomes in both price-setting and quantity-setting competitions.

By building a simple extention of the model from Matsumura and Ogawa [6] in line with Hoernig [2], Nakamura [3], and Nakamura [4], we find that a sufficiently high level of network effects reverses the ranking order of the equilibrium social welfare between price-setting competition and quantity-setting competition. Thus, when the strength of network effects is sufficiently high, the equilibrium social welfare can be higher in quantity competition than in price-setting competition, because the relatively large total output levels in the former yield a strictly positive influence on equilibrium social welfare in accordance with the sufficiently high level of network effects. Therefore, in a mixed market, the superiority of price-setting competition is weakened if network effects such as consumers' expectations about each firm's equilibrium market share are sufficiently strong.

\section{Model}

We formulate a mixed duopolistic model composed of one public firm and one private firm, with an additional term that reflects the network effects introduced in Katz 
and Shapiro [1] and applied by Hoernig [2], Nakamura [3], and Nakamura [4]. We assume that firm 0 is a welfare-maximizing public firm, whereas firm 1 is a pure profit-maximizing private firm. Similar to Hoernig [2], Nakamura [3], and Nakamura [4], firm $i$ faces a linear demand of the following form:

$$
q_{i}=a+n y_{i}-p_{i}+b p_{j} \text { and } i=0,1 ; i \neq j,
$$

where $a>0$ and $b \in(0,1)$ are demand parameters. $n \in[0,1)$ indicates the strength of network effects, and $y_{i}$ is consumers' expectations on firm $i$ 's equilibrium market share. As explained in Hoernig [2], Nakamura [3], and Nakamura [4], the above demand system can be derived from the following quasi-linear concave utility function of a representative consumer:

$$
\begin{aligned}
& U\left(q_{0}, q_{1} ; y_{0}, y_{1}\right)=m+\frac{a\left(q_{0}+q\right)}{1-b}-\frac{q_{0}^{2}+q_{1}^{2}}{2\left(1-b^{2}\right)}-\frac{b q_{0} q_{1}}{1-b^{2}} \\
& +n \frac{\left(y_{0}+b y_{1}\right) q_{0}+\left(y_{1}+b y_{0}\right) q_{1}}{1-b^{2}}+f\left(y_{0}, y_{1}\right),
\end{aligned}
$$

where $m$ denotes the income of the representative consumer and $f(\cdot, \cdot)$ represents some symmetric function of expectations. In this paper, in the same manner as in Hoernig [2], Nakamura [3], and Nakamura [4], we suppose that

$$
f\left(y_{0}, y_{1}\right)=-n\left(y_{0}^{2} / 2+b y_{0} y_{1}+y_{1}^{2} / 2\right) /\left(1-b^{2}\right)^{2} .
$$

The marginal cost of production of both firms 0 and 1 is commonly assumed to be $c$. The profit function of firm $i$ is given by $\Pi_{i}=\left(p_{i}-c\right) q_{i}, \quad(i, j=0,1 ; i \neq j)$ where $q_{i}$ is given as $(1)^{3}$. Consumer surplus is expressed as the representative consumer's utility as follows:

$$
C S=U\left(q_{0}, q_{1} ; y_{0}, y_{1}\right)-p_{0} q_{0}-p_{1} q_{1},
$$

whereas producer surplus is given by the sum of the profits of both firms 0 and $1, \Pi_{0}+\Pi_{1}$. Finally, we suppose that social welfare is defined as the sum of consumer surplus and producer surplus.

We consider "rational expectations" to be a subgame perfect Nash equilibrium by imposing the rational expectations condition that $y_{0}=q_{0}$ and $y_{1}=q_{1}$ à la Katz and Shapiro [1], Hoernig [2], Nakamura [3], and Nakamura [4].

\section{Welfare Analysis}

\section{1. p-p Game}

In this subsection, we discuss the $p$ - $p$ game where firms 0

${ }^{2}$ This assumption in the form of $f(\cdot, \cdot)$ implies that the representative consumer's utility is the highest with respect to the consumption vector of the goods produced by both the public firm and the private firm, $\left(q_{0}, q_{1}\right)$, when expectations are rational and correct.

${ }^{3}$ We assume that $a /(1-b)>c \geq 0$ in order to ensure the non-negativity of all equilibrium outcomes. and 1 simultaneously choose their price levels. By considering $y_{0}$ and $y_{1}$ as given, public firm 0 maximizes the social welfare with respect to $p_{0}$ whereas private firm 1 maximizes its profit with respect to $p_{1}$. In this case, the social welfare is given as follows:

$$
\begin{aligned}
& W\left(p_{0}, p_{1} ; y_{0}, y_{1}\right) \\
& =-\frac{\left(1-b^{2}\right) p_{0}^{2}}{2\left(1-b^{2}\right)}+\frac{p_{0}\left[2(1-b)\left(1-b^{2}\right) c+2 b p_{1}-2 b^{3} p_{1}\right]}{2\left(1-b^{2}\right)} \\
& +\frac{2 a^{2}(1+b)-p_{1}^{2}+b^{2} p_{1}^{2}-n y_{0}^{2}+n^{2} y_{0}^{2}-2 b n y_{0} y_{1}}{2\left(1-b^{2}\right)} \\
& +\frac{2 b n^{2} y_{0} y_{1}-n y_{1}^{2}+n^{2} y_{1}^{2}}{2\left(1-b^{2}\right)} \\
& -\frac{2 a(1+b)\left[2(1-b) c-n\left(y_{0}+y_{1}\right)\right]}{2\left(1-b^{2}\right)} \\
& +\frac{2\left(1-b^{2}\right) c\left[(1-b) p_{1}-n\left(y_{0}+y_{1}\right)\right]}{2\left(1-b^{2}\right)} .
\end{aligned}
$$

Note that the term of the price level of firm $0, p_{0}$ is independent of the term of consumers' expectations about the market share of both firms 0 and $1, y_{0}$ and $y_{1}{ }^{4}$. On the other hand, the profit of firm 1 is given as follows:

$$
\Pi_{1}\left(p_{0}, p_{1} ; y_{0}, y_{1}\right)=\left(p_{1}-c\right)\left(a+b p_{0}-p_{1}+n y_{1}\right) .
$$

The respective reaction functions of firms 0 and $1, r_{i}$, are given as follows $(i=0,1)$ :

$$
\begin{aligned}
& p_{0}=r_{0}\left(p_{1}\right)=c-b c+b p_{1}, \\
& p_{1}=r_{1}\left(p_{0} ; y_{1}\right)=\left(a+c+b p_{0}+n y_{1}\right) / 2 .
\end{aligned}
$$

Note that the price level of firm 0 does not depend on consumers' expectations about the market share of both firms 0 and 1 in its reaction function.

We obtain the rational expectations Nash equilibrium outcomes by substituting the rational expectations assumption that $y_{0}=q_{0}$ and $y_{1}=q_{1}$ into Equations (2) and (3). The equilibrium market outcomes namely the output and price levels of firms 0 and 1, profit of firm 0 , producer surplus and consumer surplus are given as follows:

$$
\begin{aligned}
& q_{0}^{p p}=\frac{a-(1-b) c}{1-n}, q_{1}^{p p}=\frac{a-(1-b) c}{2-b^{2}-n}, \\
& p_{0}^{p p}=\frac{a b+c(2-b-n)}{2-b^{2}-n}, p_{1}^{p p}=c+\frac{a-(1-b) c}{2-b^{2}-n},
\end{aligned}
$$

${ }^{4}$ Thus, as described below, in firm 0's reaction function, its price level does not depend on consumers' expectations about the market share of both firms 0 and $1, y_{0}$ and $y_{1}$. 


$$
\begin{array}{cl}
\Pi_{0}^{p p}=\frac{b[a-(1-b) c]^{2}}{(1-n)\left(2-b^{2}-n\right)}, & \begin{array}{c}
C S^{p p} \\
=\frac{[a-(1-b) c]^{2}\left[5-b+b^{3}-6 n+2 n^{2}-b^{2}(3-2 n)\right]}{2(1-b)(1-n)\left(2-b^{2}-n\right)^{2}}+m .
\end{array} \\
P S^{p p}=\frac{(1+b)[a-(1-b) c]^{2}\left(1+b-b^{2}-n\right)}{(1-n)\left(2-b^{2}-n\right)^{2}}, & \begin{array}{c}
\text { Furthermore, the payoffs of both firms } 0 \text { and } 1 \text { are } \\
\text { given as follows: }
\end{array} \\
W^{p p}=\frac{[a-(1-b) c]^{2}\left[7+b-b^{3}+2 b^{4}-2(4-n) n-b^{2}(7-4 n)\right]}{2(1-b)(1-n)\left(2-b^{2}-n\right)^{2}}+m, \\
\Pi_{1}^{p p}=\frac{[a-(1-b) c]^{2}}{\left(2-b^{2}-n\right)^{2}}
\end{array}
$$

Furthermore, the payoffs of both firms 0 and 1 are

\section{2. q-q Game}

In this subsection, we discuss the $q-q$ game where firms 0 and 1 simultaneously choose their output levels. By considering $y_{0}$ and $y_{1}$ as given, public firm 0 maximizes the social welfare with respect to $q_{0}$ whereas private firm 1 maximizes its profit with respect to $q_{1}$. In this case, the social welfare is given as follows:

$$
\begin{aligned}
W\left(q_{0}, q_{1} ; y_{0}, y_{1}\right)= & \frac{2 a(1+b)\left(q_{0}+q_{1}\right)-q_{0}^{2}+2 b q_{0} q_{1}+q_{1}^{2}-2\left(1-b^{2}\right) c\left(q_{0}+q_{1}\right)}{2\left(1-b^{2}\right)} \\
& +\frac{2 n q_{0} y_{0}+2 b n q_{1} y_{0}-n y_{0}^{2}+2 b n q_{0} y_{1}+2 n q_{1} y_{1}-2 b n y_{0} y_{1}-n y_{1}^{2}}{2\left(1-b^{2}\right)} .
\end{aligned}
$$

On the other hand, the profit of firm 1 is given as follows:

$$
\Pi_{1}\left(q_{0}, q_{1} ; y_{0}, y_{1}\right)=q_{1}\left[\frac{a(1+b)-b q_{0}-q_{1}+b n y_{0}+n y_{1}}{1-b^{2}}-c\right]
$$

The respective reaction functions of firms 0 and $1, r_{i}$ are given as follows $(i=0,1)$ :

$$
q_{0}=r_{0}\left(q_{1} ; y_{0}, y_{1}\right)=a(1+b)-\left(1-b^{2}\right) c-b q_{1}+n y_{0}+b n y_{1}
$$

$$
\begin{aligned}
q_{1} & =r_{1}\left(q_{0}, y_{0}, y_{1}\right) \\
& =\left[a(1+b)-\left(1-b^{2}\right) c-b q_{0}+b n y_{0}+n y_{1}\right] / 2 .
\end{aligned}
$$

We obtain the rational expectations Nash equilibrium outcomes by substituting the rational expectations assumption that $y_{0}=q_{0}$ and $y_{1}=q_{1}$ into Equations (4) and (5), The equilibrium market outcomes including the output and price levels of firms 0 and 1 , profit of firm 0 , and consumer surplus are given as follows:

$$
\begin{aligned}
& q_{0}^{q q}=\frac{(1+b)[a-(1-b) c][2-b(1-n)-n]}{\left[2-b^{2}(1-n)-n\right](1-n)}, q_{1}^{q q}=\frac{\left(1-b^{2}\right)[a-(1-b) c]}{2-b^{2}(1-n)-n}, p_{0}^{q q}=c, \\
& p_{1}^{q q}=c+\frac{a-(1-b) c}{2-b^{2}(1-n)-n}, \Pi_{0}^{q q}=0, \\
& P S^{q q}=\frac{\left(1-b^{2}\right)[a-(1-b) c]^{2}}{\left[2-b^{2}(1-n)-n\right]^{2}}, \\
& C S^{q q}=\frac{(1+b)[a-(1-b) c]^{2}\left[5-2 b^{2}(2-n)(1-n)-2 b(1-n)^{2}+2 b^{3}(1-n)^{2}-2(3-n) n\right]}{2(1-b)\left[2-b^{2}(1-n)-n\right]^{2}(1-n)}+m .
\end{aligned}
$$

Furthermore, the payoffs of both firms 0 and 1 are given as follows: 


$$
\begin{aligned}
W^{q q} & =\frac{[a-(1-b) c]^{2}\left[7+b-4 b^{2}(2-n)(1-n)+2 b^{4}(1-n)^{2}-2(4-n) n\right]}{(1-b)\left[2-b^{2}(1-n)-n\right]^{2}(1-n)}+m, \\
\Pi_{1}^{q q} & =\frac{\left(1-b^{2}\right)[a-(1-b) c]^{2}}{\left[2-b^{2}(1-n)-n\right]^{2}} .
\end{aligned}
$$

On comparing the equilibrium social welfare between price-setting competition and quantity competition, we obtain the following result:

$$
\begin{aligned}
W^{p p}-W^{q q} & =\frac{b^{2}[a-(1-b) c]^{2}\left[4+b^{4}(1-n)^{2}-8 n+3 n^{2}-b^{2}\left(4-8 n+3 n^{2}\right)\right]}{2\left[2-b^{2}(1-n)-n\right]^{2}(1-n)\left(2-b^{2}-n\right)^{2}} \gtreqless 0 \\
& \Leftrightarrow n \lesseqgtr \frac{4-4 b^{2}+b^{4}-\left(2-b^{2}\right) \sqrt{1-b^{2}}}{3-3 b^{2}+b^{4}}(\in(0,1), \forall b \in(0,1)) .
\end{aligned}
$$

Then, we obtain the proposition on the ranking order of equilibrium social welfare between price-setting competition and quantity-setting competition.

Proposition 1 When the strength of network effects in a mixed duopoly is sufficiently high, that is, $n>\left[4-4 b^{2}+b^{4}-\left(2-b^{2}\right) \sqrt{1-b^{2}}\right] /\left(3-3 b^{2}+b^{4}\right)$, the equilibrium social welfare is higher in quantity-setting competition than in price-setting competition; otherwise the opposite is the case.

In Figure 1, the difference in the equilibrium social welfare between price-setting competition and quantitysetting competition is described. Surprisingly, Proposition 1 implies that when the strength of network effects is sufficiently high, the result on the ranking order of the equilibrium social welfare between a price-setting competition and a quantity-setting competition obtained in Ghosh and Mitra [5] and Matsumura and Ogawa [6] is totally reversed; hence, the equilibrium social welfare can be higher in quantity-setting competition than in pricesetting competition. The intuition behind this result is given by using the following lemma:

Lemma 1 For the rational expectations Nash equilibrium in price and quantity competitions, the ranking orders of the equilibrium market outcomes are given as follows:

1) $p_{0}^{p p}>p_{0}^{q q}, p_{1}^{p p} \geq p_{1}^{q q}, q_{0}^{q q}>q_{0}^{p p}$, and $q_{1}^{p p}>q_{1}^{q q}$,

2)

2) $\begin{aligned} & \left(q_{0}^{q q}+q_{1}^{q q}\right)>\left(q_{0}^{p p}+q_{1}^{p p}\right) \text { and } \\ & \left(q_{0}^{q q}-q_{1}^{q q}\right)>\left(q_{0}^{p p}-q_{1}^{p p}\right) \\ & \text { 3) } P S^{p p}>P S^{q q} \text { and } C S^{q q}>C S^{p p} .\end{aligned}$

Note that the above equality of the price level of private firm 1 is satisfied only when $n=0^{5}$.

From Lemma 1, even if network effects are introduced,

${ }^{5}$ When $n=0$, the fact that such an equality holds is indicated in Ghosh and Mitra [5]. the ranking orders of equilibrium outcomes except for the price level of firm 1 are the same as those obtained in Ghosh and Mitra [5]. The introduction of network effects widens the difference in the price level of firm 0 between price-setting competition and quantity-setting competition, implying that such a low level of $p_{0}^{q q}$ creates a strong downward pressure on firm 1's price level. Thus, when $n$ takes some sort of positive value, firm 0's price level is strictly higher in price-setting competition than in quantity-setting competition. Therefore, in particular when the strength of network effects is sufficiently low, since the ranking order of the equilibrium market outcomes seldom changes against the introduction of network effects, the equilibrium social welfare is higher in price competition than in quantity competition owing to the large difference of the equilibrium producer surplus relative to that of the equilibrium consumer surplus, which is similar to Ghosh and Mitra [5] and Matsumura and Ogawa [6].

On the other hand, by following the formula of equilibrium social welfare à la Ghosh and Mitra [5], and by imposing the rational expectations condition that $y_{0}=q_{0}$ and $y_{1}=q_{1}$, we can represent the equilibrium social welfare as follows:

$$
\begin{aligned}
& W\left(q_{0}, q_{1} ; y_{0}=q_{0}, y_{1}=q_{1}\right)=s\left(q_{0}+q_{1}\right)+d\left(q_{0}-q_{1}\right), \\
& \text { where }\left\{\begin{array}{r}
s\left(q_{0}+q_{1}\right)=[a-(1-b) c]\left(q_{0}+q_{1}\right) /(1-b) \\
-(1-n)\left(q_{0}+q_{1}\right)^{2} / 4(1-b), \\
d\left(q_{0}-q_{1}\right)=-(1-n)\left(q_{0}-q_{1}\right)^{2} / 4(1+b) .
\end{array}\right.
\end{aligned}
$$

As explained in Ghosh and Mitra [5] and Matsumura and Ogawa [6], on the basis of the facts that $s^{\prime}(\cdot)>0$ and $d^{\prime}(\cdot)<0$, the effect of $d\left(q_{0}-q_{1}\right)$ on the equilibrium social welfare outstrips the effect of $s\left(q_{0}+q_{1}\right)$ when $n=0$; consequently, the equilibrium social wel- 


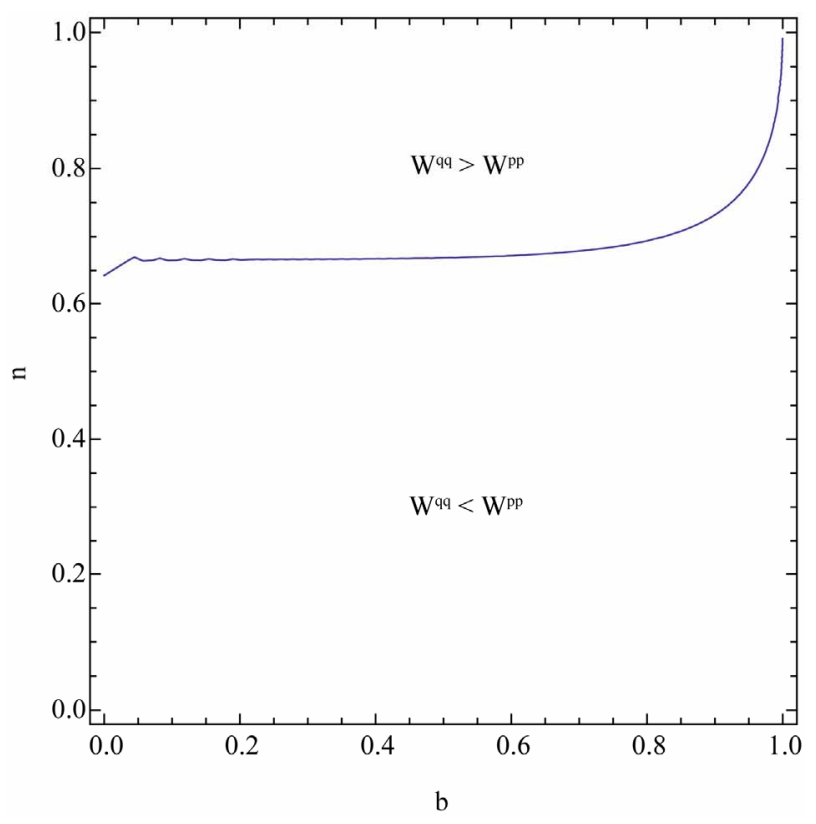

Figure 1. Comparison of the equilibrium social welfare between price-setting competition and quantity-setting competition.

fare is higher in price-setting competition than in quantity-setting competition if no network effects are considered. However, as $n$ becomes higher, in a quantitysetting competition, the positive effect of $s\left(q_{0}+q_{1}\right)$ owing to $\left(q_{0}^{q q}+q_{1}^{q q}\right)>\left(q_{0}^{p p}+q_{1}^{p p}\right)$ on the equilibrium social welfare increases. On the other hand, the negative effect of $d\left(q_{0}-q_{1}\right)$ owing to $\left(q_{0}^{q q}-q_{1}^{q q}\right)>\left(q_{0}^{p p}-q_{1}^{p p}\right)$ on the equilibrium social welfare decreases. Therefore, the degree of the strength of network effects, $n$, reverses the order of the equilibrium social welfare between pricesetting and quantity-setting competitions.

\section{Conclusions}

This study compared the equilibrium social welfare between price-setting competition and quantity-competition in a mixed duopolistic market with network effects. In Ghosh and Mitra [5] and Matsumura and Ogawa [6], where network effect is not considered, it was shown that the equilibrium social welfare is always higher in pricesetting competition than in quantity competition ${ }^{6}$. However, in this paper, when the strength of network effects is sufficiently high, we found that the ranking order of the equilibrium social welfare between price-setting competition and quantity-setting competition is totally reversed. Thus, when network effects are explicitly considered, the superiority of price competition with regard to social welfare weakens in a mixed duopolistic market.

Furthermore, by following Matsumura and Ogawa [6], where public firm 0 and private firm 1 can choose their strategic variables (i.e., their price levels or output levels), even if the network effects are explicitly introduced, we obtain the same results as those in their paper. Thus, in the two-stage game wherein both firms 0 and 1 simultaneously choose either their price contracts or their quantity contracts in the first stage, and accordingly engage in market competition in the second stage, we find that price-setting competition is a unique market competition structure led by dominant strategies such that both the firms take the price contracts ${ }^{7}$.

\section{REFERENCES}

[1] M. Katz and C. Shapiro, "Network Externalities, Competition, and Compatibility,” American Economic Review, Vol. 75, No. 3, 1985, pp. 424-440.

[2] S. Hoernig, "Strategic Delegation under Price Competition and Network Effects," Economics Letters, Vol. 117, No. 2, 2012, pp. 487-489.

doi:10.1016/j.econlet.2012.06.045

[3] Y. Nakamura, "Capacity Choice in a Price-Setting Mixed Duopoly with Network Effects,” Modern Economy, Vol. 4, No. 5, 2013, pp. 418-425. doi:10.4236/me.2013.45044

[4] Y. Nakamura, "Endogenous Timing in Price-Setting Private and Mixed Duopoly with Network Effects," 2013, Mimeograph.

[5] C. Ghosh and M. Mitra, "Comparing Bertrand and Cournot in Mixed Markets,” Economics Letters, Vol. 109, No. 2, 2010, pp. 72-74. doi:10.1016/j.econlet.2010.08.021

[6] T. Matsumura and A. Ogawa, "Price versus Quantity in a Mixed Duopoly," Economics Letters, Vol. 116, No. 2, 2012, pp. 174-177. doi:10.1016/j.econlet.2012.02.012

[7] J. C. Bárcena-Ruiz and M. B. Garzón, "Mixed Duopoly, Merger and Multiproduct Firms,” Journal of Economics, Vol. 80, No. 1, 2003, pp. 27-42. doi:10.1007/s00712-002-0605-2

\footnotetext{
${ }^{6}$ Matsumura and Ogawa [6] found that the equilibrium social welfare becomes higher in price competition than in quantity competition regardless of the relation of goods produced by both the firms, that is, substitutable goods or complementary goods.
}

${ }^{7}$ Detailed discussions and proofs on the above are available upon request. 